\title{
Características produtivas e qualitativas de pastagem de braquiária em monocultivo e consorciada com estilosantes ${ }^{(1)}$
}

\author{
Domingos Sávio Campos Paciullo(2), Luiz Januário Magalhães Aroeira ${ }^{(2)}$, Maurílio José Alvim(2) \\ e Margarida Mesquita Carvalho(2)
}

\begin{abstract}
Resumo - O objetivo deste trabalho foi avaliar a massa de forragem e a composição botânica de pastagens de Brachiaria decumbens Stapf em monocultivo e consorciada com Stylosanthes guianensis (Aubl.) Sw. var. vulgaris cv. Mineirão, em diferentes meses do ano. As amostras obtidas em janeiro e maio foram submetidas a ensaio de degradabilidade in situ da matéria seca. Foram utilizados três piquetes (repetições), cada um dividido em duas parcelas (monocultura e consorciação). Após cada amostragem, o pasto foi submetido a pastejo com vacas secas. A massa de forragem de $B$. decumbens não variou com o sistema de cultivo; foi menor no mês de outubro $(291 \mathrm{~kg} / \mathrm{ha})$ e não diferiu entre os demais meses $(1.571 \mathrm{~kg} / \mathrm{ha})$. A massa de forragem da leguminosa decresceu ao longo do ano e sua porcentagem na pastagem foi maior em outubro/2001 e menor em janeiro/2002. A massa de forragem total na pastagem consorciada $(2.158 \mathrm{~kg} / \mathrm{ha})$ foi maior que a do monocultivo $(1.481 \mathrm{~kg} / \mathrm{ha})$. A taxa de degradação e a degradabilidade efetiva média de $S$. guianensis foram, respectivamente, de $6,8 \% / \mathrm{h}$ e $61,5 \%$, e de B. decumbens foram de $5,3 \% / \mathrm{h}$ e $49,2 \%$. A leguminosa contribui no aumento da quantidade e na melhoria da qualidade da forragem disponível na pastagem.
\end{abstract}

Termos para indexação: Brachiaria decumbens, Stylosanthes guianensis, leguminosa forrageira, produção de forragem, pastagem mista, valor nutritivo.

\section{Productive and qualitative traits of Brachiaria decumbens pasture in monoculture and associated with Stylosanthes guianensis}

\begin{abstract}
The objective of this work was to evaluate the forage mass and botanical composition of Brachiaria decumbens Stapf pasture in monoculture and associated with Stylosanthes guianensis (Aubl.) Sw. var. vulgaris cv. Mineirão in various months along the year. The samples from January and May were rumen incubated. Three paddocks (replications) were divided in two plots (monoculture and associated pastures). After the evaluations forage was grazed by dried cows. The forage mass of B. decumbens did not vary with the pasture system; in October it was lower $(291 \mathrm{~kg} / \mathrm{ha})$ and maintained stable along the other months $(1,571 \mathrm{~kg} / \mathrm{ha})$. A decrease tendency of legume forage mass was observed during the experimental period. The proportion of S. guianensis in the pasture was higher in October/ 2001 and lower in January $/ 2002$. The total forage mass of associated pasture $(2,158 \mathrm{~kg} / \mathrm{ha})$ was higher than the monoculture pasture $(1,481 \mathrm{~kg} / \mathrm{ha})$. The degradation rates and effective degradability of S. guianensis and B. decumbens were respectively $6.8 \% / \mathrm{h}$ and $61.5 \%$ and $5.3 \% / \mathrm{h}$ and $49.2 \%$. The legume contribute for higher quantity and better quality forage available in associated pasture.
\end{abstract}

Index terms: forage legume, forage production, mixed pastures, nutritive value.

\section{Introdução}

A baixa fertilidade natural dos solos é fator limitante da produtividade e sustentabilidade das

\footnotetext{
(1)Aceito para publicação em 17 de dezembro de 2002.

(2)Embrapa-Centro Nacional de Pesquisa de Gado de Leite, Rua Eugênio do Nascimento, 610, Dom Bosco, CEP 36038-330 Juiz de Fora, MG. Bolsista do CNPq. E-mail: dscp@terra.com.br, laroeira@cnpgl.embrapa.br, alvim@cnpgl.embrapa.br, mmcarval@cnpgl.embrapa.br
}

pastagens tropicais, assim como o manejo que também pode acentuar a deficiência de nutrientes, especialmente o nitrogênio. $\mathrm{O}$ aumento do suprimento de N no solo, na melhoria da produtividade das gramíneas, pode ser obtido pela aplicação de fertilizantes nitrogenados ou pelo uso de leguminosas em consorciação com gramíneas, por causa da capacidade dessas plantas em fixar biologicamente o $\mathrm{N}$ atmosférico (Giller \& Cadisch, 1995). O N fixado pelas leguminosas contribui para o sistema de produção, 
pois melhora a qualidade da dieta (Leopoldino, 2000) e aumenta a produção animal (Euclides et al., 1998). A contribuição é feita indiretamente pela transferência do $\mathrm{N}$ fixado para a gramínea, o que aumenta a capacidade de suporte da pastagem e prolonga a sua capacidade produtiva (Cantarutti \& Boddey, 1997). Outra vantagem das leguminosas é a menor variação estacional no seu valor nutritivo, em comparação com as gramíneas forrageiras (Klusmann, 1988).

As leguminosas são capazes de fixar quantidades de $\mathrm{N}$ que contribuem na melhoria da fertilidade do solo e no aumento da produção de forragem. Em estudo para avaliar o efeito da reciclagem de $\mathrm{N}$ em pastagem consorciada de B. decumbens com Calopogonium mucunoides, a leguminosa reciclou $63 \mathrm{~kg} / \mathrm{ha} /$ ano de N, resultando em aumentos na disponibilidade de $\mathrm{N}$ para a gramínea e no teor de proteína bruta da forragem disponível (Seiffert et al., 1985). Boddey et al. (1996) também constataram que a consorciação de Andropogon gayanus com Stylosanthes spp. proporcionou à pastagem 67 a $117 \mathrm{~kg} / \mathrm{ha}$ de nitrogênio.

O fracasso na adoção e utilização de pastagens consorciadas, em geral, é atribuído à baixa persistência das leguminosas nas pastagens, o que está associado à quase ausência de germoplasma perfeitamente adaptado às condições edafoclimáticas brasileiras, à falta de técnicas de manejo específicas ou eficientes para essas pastagens e à adubação inadequada (Leite \& Euclides, 1994).

Trabalhos citados por Barcellos \& Vilela (1994) demonstraram a boa persistência de cultivares de Stylosanthes guianensis sob pastejo. Segundo esses autores, esta espécie apresenta retenção de folhas durante a seca, constituindo-se boa fonte de forragem.

O objetivo deste trabalho foi avaliar a massa de forragem, a composição botânica e a degradabilidade da matéria seca de pastagem de Brachiaria decumbens em monocultivo e consorciada com Stylosanthes guianensis var. vulgaris cv. Mineirão, em diferentes meses do ano.

\section{Material e Métodos}

O experimento foi realizado na Embrapa-Centro Nacional de Pesquisa de Gado de Leite, em Coronel Pacheco,
MG, de janeiro de 2001 a janeiro de 2002. A pastagem foi estabelecida num Latossolo Vermelho-Amarelo de baixa fertilidade entre faixas plantadas com espécies arbóreas, em área de topografia montanhosa com declividade de aproximadamente $30 \%$. A região apresenta precipitação média mensal de $60 \mathrm{~mm}$ e temperatura média de $17^{\circ} \mathrm{C}$, de abril a setembro, e de $230 \mathrm{~mm}$ e $24^{\circ} \mathrm{C}$, de outubro a março.

$\mathrm{Na}$ avaliação da massa de forragem e composição botânica, foram utilizados três piquetes com área de 0,5 ha; metade foi cultivada com Brachiaria decumbens, em monocultivo, e a outra metade com B. decumbens + Stylosanthes guianensis, em consorciação. Antes da semeadura, em novembro de 1997, aplicaram-se $1.000 \mathrm{~kg} / \mathrm{ha}$ de calcário dolomítico, $600 \mathrm{~kg} / \mathrm{ha}$ de fosfato de Araxá, $25 \mathrm{~kg} / \mathrm{ha}$ de superfosfato simples, $100 \mathrm{~kg} / \mathrm{ha}$ de cloreto de potássio e $30 \mathrm{~kg} / \mathrm{ha}$ de FTE BR-16. As densidades de semeadura foram 10 e $1 \mathrm{~kg} / \mathrm{ha}$ de $B$. decumbens e S. guianensis, respectivamente.

Foi adotado o delineamento de blocos completos casualizados, em esquema de parcelas subdivididas no tempo, com três repetições. As parcelas principais eram constituídas pelos tipos de cultivos (gramínea em monocultivo ou consorciada) e as subparcelas, pelos meses de avaliação.

As estimativas da massa de forragem e composição botânica foram realizadas em janeiro, março, maio, outubro e dezembro/2001 e em janeiro/2002. Após cada amostragem, os piquetes eram submetidos a pastejo com vacas secas, mestiças Holandês x Zebu, durante dez dias consecutivos, exceto durante o mês de outubro, quando a baixa quantidade de forragem disponível impossibilitou o pastejo.

As amostras para avaliação da massa de forragem e da composição botânica foram obtidas com auxílio de um quadrado de $0,5 \mathrm{~m}$ de lado, lançado dez vezes, ao acaso, em cada parcela. A forragem contida em cada quadrado foi cortada a cinco centímetros do nível do solo e levada ao laboratório, onde foi separada manualmente em B. decumbens, S. guianensis e material morto. De cada espécie foi retirada uma subamostra para separação das frações lâmina foliar e bainha foliar + colmo. Cada componente foi pesado e secado em estufa a $65^{\circ} \mathrm{C}$ para determinação da matéria seca (MS).

Foram analisadas a degradabilidade da MS e a composição química, nas amostras obtidas nos meses de janeiro e maio, por meio do pastejo simulado, e colhidas as partes das plantas que são potencialmente pastejadas pelos animais (folhas e colmos tenros). Após serem secadas a $55^{\circ} \mathrm{C}$ por 72 horas e moídas, as amostras foram analisadas quanto aos teores de proteína bruta (PB), segundo Association 
of Official Analytical Chemists (1990), e de fibra detergente neutro (FDN), de acordo com Soest et al. (1991).

No ensaio de degradabilidade da MS, aproximadamente 5,0 g de forragem seca moída a $5 \mathrm{~mm}$ foram acondicionadas em sacos de náilon e incubadas por $0,2,6,12,24,48$ e 72 horas em quatro vacas mestiças Europeu x Zebu, fistuladas no rúmen, num delineamento em blocos casualizados, com quatro repetições. A degradabilidade foi estimada por meio das determinações da $\mathrm{MS}$ a $105^{\circ} \mathrm{C}$, na amostra original e no conteúdo residual de cada saco.

As variáveis da degradabilidade foram calculadas a partir da seguinte equação:

$\mathrm{Y}(\mathrm{t})=\mathrm{a}+\mathrm{b}\left(1-\mathrm{e}^{-\mathrm{ct}}\right)$,

em que a é a fração solúvel em água; b é a fração insolúvel em água, potencialmente degradável; e c é a taxa de degradação da fração $b$.

A degradabilidade efetiva (DE) da MS foi calculada usando a seguinte equação:

$\mathrm{DE}=\mathrm{a}+(\mathrm{b} . \mathrm{c}) /(\mathrm{c}+\mathrm{k})$,

em que ké a taxa de passagem das partículas no rúmen (adotou-se a taxa de $0,03 / \mathrm{h}$ ).

Ambas as equações foram propostas por Orskov \& McDonald (1979). Os dados obtidos foram submetidos à análise de variância e as médias comparadas pelo teste de Tukey a $5 \%$ de probabilidade.

\section{Resultados e Discussão}

A massa de forragem de $B$. decumbens e a quantidade de material morto das pastagens não variaram com o sistema de cultivo nem com a interação sistema de cultivo $\mathrm{x}$ mês do ano (Tabela 1). Os valores médios foram de 1.357 e $1.376 \mathrm{~kg} / \mathrm{ha}$, respectivamente, em $B$. decumbens e material morto. Mesmo com menor área para crescimento, por causa da presença da leguminosa na pastagem, $B$. decumbens consorciada com $S$. guianensis apresentou massa de forragem semelhante à da monocultura. É possível que a leguminosa tenha aumentado a quantidade de $\mathrm{N}$ no solo, contribuindo para o crescimento da gramínea. A alta quantidade de material morto na pastagem sugere que a decomposição dos tecidos vegetais constituiu importante via de transferência do $\mathrm{N}$ para $B$. decumbens. Este fato encontra respaldo na observação de Cantarutti \& Boddey (1997), de que a reciclagem e a transferência do $\mathrm{N}$ através dos resíduos vegetais são mais significativas nos sistemas de exploração extensivos de pastagens.
A massa de forragem total não variou com a interação sistema de cultivo x mês do ano, mas revelou efeitos isolados do tipo de cultivo e do mês do ano (Tabela 2). Os maiores valores foram observados de janeiro a maio e em dezembro de 2001, e o menor, em outubro, final do período de menores precipitação pluvial, temperatura e luminosidade. Quanto ao tipo de cultivo, foi observado valor mais elevado de massa de forragem total na pastagem consorciada em relação à monocultura (Tabela 2). Os valores de massa de forragem total acumulados durante os seis períodos de avaliação foram de $8.887 \mathrm{~kg} / \mathrm{ha}$ (pastagem em monocultura) e $12.949 \mathrm{~kg} / \mathrm{ha}$ (consorciada). Além de influenciar no crescimento da gramínea, S. guianensis contribuiu para o aumento da massa de forragem total da pastagem consorciada. Gonçalves \& Costa (1994) e Ibrahim \& Mannetje (1998) também encontraram aumento significativo na massa de forragem das pastagens consorciadas quando comparadas com o cultivo exclusivo de gramíneas.

O comprometimento da quantidade de forragem durante o mês de outubro deveu-se, principalmente, à baixa produção de $B$. decumbens (Figura 1). As massas de forragem de B. decumbens e $S$. guianensis decresceram em outubro $81 \%$ e $23 \%$, respectivamente, quando comparadas com a média dos três primeiros meses de avaliação. Este fato explica a proporção mais elevada da leguminosa na pastagem durante o mês de outubro $(69 \%)$ e realça a importância de sua participação na forragem produzida durante a época seca do ano.

Entretanto, enquanto os valores de massa de forragem da gramínea aumentaram a partir de dezembro, os da leguminosa continuaram a decrescer, o que refletiu na mais baixa proporção $(22,4 \%)$ de S. guianensis na pastagem durante o mês de janeiro/ 2002. Reduções mais acentuadas na porcentagem de leguminosas, quando consorciadas com B. decumbens, foram observadas por Seiffert \& Zimmer (1988), de 30\% para 6\%, e por Euclides et al. (1998), de $15 \%$ para $6 \%$, após três anos de pastejo.

A relação lâmina/colmo de $B$. decumbens não variou com o tipo de cultivo nem com a interação tipo de cultivo x mês do ano. Entretanto, foi observado efeito do mês sobre a relação lâmina/colmo das espécies (Figura 2). A comparação entre os dados de $B$. decumbens (média dos valores obtidos na pasta- 
gem em monocultura e no consórcio) e de S. guianensis revelou maiores valores da relação lâmina/colmo na gramínea $(0,71$ a 0,95$)$ em relação à leguminosa $(0,54$ a 0,68$)$. A única exceção foi observada em outubro, quando os valores foram semelhantes $(0,71$ e 0,68 , respectivamente em B. decumbens e $S$. guianensis) (Figura 2).

Baseado na massa de forragem e na relação lâmina/colmo de cada espécie foi possível calcular a massa de folhas. Os valores variaram de 180 a $810 \mathrm{~kg} / \mathrm{ha}$ (gramínea) e de 200 a $480 \mathrm{~kg} / \mathrm{ha}$ (leguminosa) (Figura 2). A contribuição porcentual de lâminas foliares na produção total de forragem é importante porque reflete melhor a qualidade da forragem à disposição dos animais em pastejo. Isto se justifica pelo maior valor nutritivo das folhas em relação aos colmos, bem como pela preferência dos animais em consumirem mais folhas do que colmos em regime de pastejo (Chacon et al., 1978). A baixa proporção média de folhas na massa total de $S$. guianensis (38\%) poderia limitar a ingestão de leguminosa por animais em pastejo. Entretanto, Euclides et al. (1998) constataram que a contribuição da leguminosa para a dieta resultou em melhor desempenho de bovinos em pastagem consorciada, relativamente aqueles mantidos em pastagem exclusiva de gramínea, mesmo quando a porcentagem de leguminosa na pastagem foi baixa.

A massa de folhas de $S$. guianensis $(360 \mathrm{~kg} / \mathrm{ha})$, no mês de outubro, foi maior que a da gramínea (180 kg/ha), o que reforça a importância da participação da leguminosa na biomassa potencialmente consumível por ruminantes, no final da época seca do ano (Figura 2).

A proporção de material morto variou conforme o mês do ano, não apresentando, contudo, efeito do sistema de cultivo nem da interação sistema de cultivo x mês (Tabela 2). Na maior parte do ano, esta proporção esteve entre $31,9 \%$ e $36,2 \%$, com exceção dos meses de maio e outubro (início e final do período seco), em que aumentou para 50,6\% e $72,2 \%$, respectivamente.

Os teores de PB de B. decumbens foram de $6,6 \% \mathrm{e}$ $8,6 \%$, e os teores de FDN foram de $66,8 \%$ e $64,8 \%$, respectivamente nos meses de janeiro e maio (Tabela 3). Esses valores de composição química foram compatíveis com as diferenças entre as variá-

Tabela 1. Massa de forragem de Brachiaria decumbens $(\mathrm{kg} / \mathrm{ha}$ de matéria seca) e quantidade de material morto (kg/ha de matéria seca) da monocultura e do consórcio, de acordo com o mês do ano ${ }^{(1)}$.

\begin{tabular}{lcccccccc}
\hline \multirow{2}{*}{ Mês/ano } & \multicolumn{3}{c}{ B. decumbens } & & \multicolumn{3}{c}{ Material morto } \\
\cline { 2 - 4 } \cline { 6 - 8 } & Monocultura & Consórcio & Média & & Monocultura & Consórcio & Média \\
\hline Janeiro/2001 & 2.034 & 1.553 & $1.793 \mathrm{~A}$ & & 1.374 & 1.143 & $1.256 \mathrm{BC}$ \\
Março/2001 & 1.543 & 1.273 & $1.408 \mathrm{AB}$ & & 1.204 & 778 & $991 \mathrm{C}$ \\
Maio/2001 & 1.645 & 1.400 & $1.523 \mathrm{AB}$ & & 2.326 & 1.894 & $2.110 \mathrm{~A}$ \\
Outubro/2001 & 271 & 312 & $291 \mathrm{C}$ & & 2.159 & 1.730 & $1.945 \mathrm{AB}$ \\
Dezembro/2001 & 1.698 & 1.322 & $1.510 \mathrm{AB}$ & & 1.121 & 1.050 & $1.086 \mathrm{C}$ \\
Janeiro/2002 & 1.696 & 1.544 & $1.620 \mathrm{~B}$ & & 942 & 782 & $862 \mathrm{C}$ \\
\hline Média & $1.481 \mathrm{a}$ & $1.234 \mathrm{a}$ & 1.357 & & $1.521 \mathrm{a}$ & $1.230 \mathrm{a}$ & 1.376 \\
\hline
\end{tabular}

${ }^{(1)}$ Médias seguidas pelas mesmas letras, minúsculas na linha e maiúsculas nas colunas, não diferem entre si pelo teste de Tukey a $5 \%$ de probabilidade.

Tabela 2. Massa de forragem total ( $\mathrm{kg} / \mathrm{ha}$ de matéria seca) da monocultura (Brachiaria decumbens) e do consórcio (Brachiaria decumbens + Stylosanthes guianensis) e proporção de material morto (\%), de acordo com o mês do ano ${ }^{(1)}$.

\begin{tabular}{|c|c|c|c|c|}
\hline Mês/ano & Monocultura & Consórcio & Média & Material morto \\
\hline Janeiro/2001 & 2.034 & 2.737 & $2.386 \mathrm{~A}$ & $35,2 \mathrm{~A}$ \\
\hline Março/2001 & 1.543 & 2.426 & $1.985 \mathrm{AB}$ & $34,7 \mathrm{~A}$ \\
\hline Maio/2001 & 1.645 & 2.561 & $2.103 \mathrm{AB}$ & $50,6 \mathrm{~B}$ \\
\hline Outubro/2001 & 271 & 1.207 & $740 \mathrm{C}$ & $72,2 \mathrm{C}$ \\
\hline Dezembro/2001 & 1.698 & 2.011 & $1.855 \mathrm{AB}$ & $36,2 \mathrm{~A}$ \\
\hline Janeiro/2002 & 1.696 & 2.007 & $1.852 \mathrm{~B}$ & $31,9 \mathrm{~A}$ \\
\hline Média & $1.481 \mathrm{~b}$ & $2.158 \mathrm{a}$ & 1.820 & 43,5 \\
\hline
\end{tabular}

(1)Médias seguidas pelas mesmas letras, minúsculas na linha e maiúsculas nas colunas, não diferem entre si pelo teste de Tukey a $5 \%$ de probabilidade. 


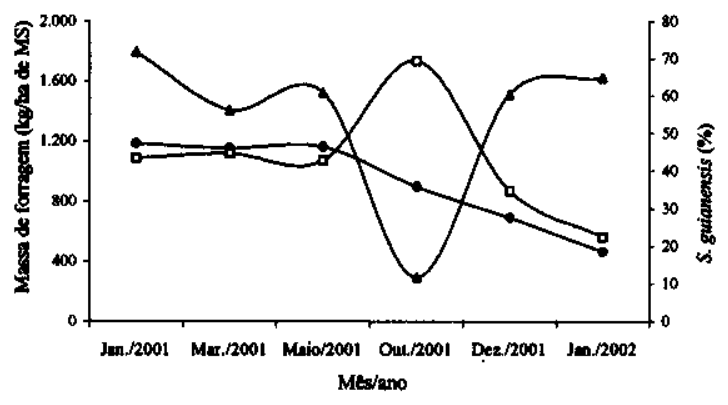

A B. decumbens $S$. guianensis $\square$ S. guianensis (\%)

Figura 1. Massa de forragem de Brachiaria decumbens (média dos dois sistemas de cultivo) e de Stylosanthes guianensis e proporção da leguminosa na pastagem, de acordo com o mês do ano.

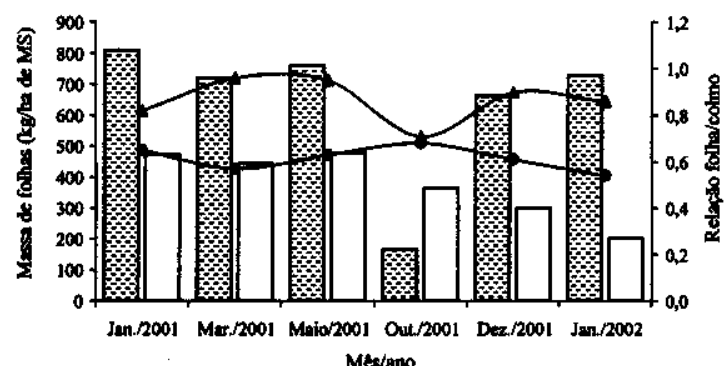

\begin{tabular}{|ll}
\hline$\square-G$ MF B. decumbens & MF S. guianensis \\
\hline F F/C B. decumbens & F/C S. guianensis
\end{tabular}

Figura 2. Massa de folhas (MF) e relação folha/colmo (F/C) de Brachiaria decumbens (média dos dois sistemas de cultivo) e de Stylosanthes guianensis, de acordo com o mês do ano. veis de degradabilidade da gramínea, visto que a taxa de degradação e a degradabilidade efetiva da MS foram mais altas em maio $(5,7 \% / \mathrm{h}$ e $52,5 \%$, respectivamente) do que em janeiro $(4,8 \% / \mathrm{h}$ e $45,9 \%)$. Os resultados demonstraram maior potencial qualitativo de $B$. decumbens durante o mês de maio. Paciullo et al. (2001) concluíram que lâminas foliares e colmos de $B$. decumbens exibiram maior valor nutritivo no outono em relação ao verão, quando se observaram menores teores de FDN e FDA e mais altas porcentagens de $\mathrm{PB}$.

S. guianensis apresentou teores de PB de $16,3 \%$ e $12,0 \%$, e de FDN de $60,9 \%$ e $54,0 \%$, respectivamente nos meses de janeiro e maio (Tabela 3). Esses resultados foram relativamente próximos aos reportados no Zimbabué (13,4\% de PB e $51,4 \%$ de FDN), numa média de 77 amostras colhidas em quatro tipos de solo (Jingura et al., 2001).

As diferenças de pequena magnitude em relação às variáveis de degradabilidade de $S$. guianensis, de acordo com os meses (Tabela 3), condizem com relatos que evidenciaram menor variação estacional no valor nutritivo de leguminosas, em comparação com as gramineas forrageiras (Klusmann, 1988). Os valores médios da taxa de degradação e da degradabilidade efetiva da leguminosa foram, respectivamente, de $6,8 \% / \mathrm{h}$ e $61,5 \%$.

$S$. guianensis apresentou variáveis de degradabilidade e teores de FDN e de PB compatíveis com as de uma forrageira de melhor valor nutricional. Por essa razão, sua presença em pastagens consorciadas além de aumentar a quantidade, pode melhorar a qualidade da forragem disponivel, principalmente na época seca do ano.

Tabela 3. Teores de proteína bruta e de fibra em detergente neutro e variáveis da degradabilidade da matéria seca de Brachiaria decumbens e de Stylosanthes guianensis, em janeiro e maio/2001.

\begin{tabular}{|c|c|c|c|c|c|c|}
\hline \multirow[t]{2}{*}{ Variável } & \multicolumn{3}{|c|}{ B. decumbens } & \multicolumn{3}{|c|}{ S. guianensis } \\
\hline & Janeiro & Maio & Média & Janeiro & Maio & Média \\
\hline Proteína bruta (\%) & 6,6 & 8,6 & 7,6 & 16,3 & 12,0 & 14,2 \\
\hline Fibra em detergente neutro (\%) & 66,8 & 64,8 & 65,8 & 60,9 & 54,0 & 57,5 \\
\hline Fração solúvel (\%) & 16,2 & 17,1 & 16,7 & 23,6 & 25,5 & 24,6 \\
\hline Fração insolúvel degradável (\%) & 48,5 & 54,2 & 51,4 & 55,6 & 51,4 & 53,5 \\
\hline Taxa de degradação (\%/h) & 4,8 & 5,7 & 5,3 & 6,5 & 7,0 & 6,8 \\
\hline Degradabilidade potencial (\%) & 62,9 & 70,3 & 66,6 & 78,7 & 76,6 & 77,7 \\
\hline Degradabilidade efetiva (\%) & 45,9 & 52,5 & 49,2 & 61,4 & 61,5 & 61,5 \\
\hline
\end{tabular}




\section{Conclusões}

1. S. guianensis contribui no aumento da massa de forragem e constitui importante fonte de forragem nas pastagens consorciadas, principalmente na época seca do ano.

2. S. guianensis melhora o valor nutritivo da forragem disponível na pastagem consorciada, por causa de seus maiores teores de PB e mais alta degradabilidade da matéria seca.

\section{Referências}

ASSOCIATION OF OFFICIAL ANALYTICAL CHEMISTS (Gaithersburg, Estados Unidos). Official methods of analysis. 15th ed. Richmond, 1990. 1298 p.

BARCELLOS, A. O.; VILELA, L. Leguminosas forrageiras tropicais: estado da arte e perspectivas futuras. In: SIMPÓSIO INTERNACIONAL DE FORRAGICULTURA, 1994, Maringá. Anais... Maringá: Sociedade Brasileira de Zootecnia, 1994. p. 1-56.

BODDEY, R. M.; ALVES JUNIOR, B.; URQUIAGA, S. Nitrogen cycling and sustainability of improved pastures in the Brazilian Cerrados. In: SIMPÓSIO SOBRE O CERRADO, 8., 1996, Brasília. Anais... Brasília: Embrapa-CPAC, 1996. p. 33-38.

CANTARUTTI, R. B.; BODDEY, R. M. Transferência de nitrogênio das leguminosas para as gramíneas. In: SIMPÓSIO INTERNACIONAL SOBRE PRODUÇÃO ANIMAL EM PASTEJO, 1997, Viçosa, MG. Anais... Viçosa, MG: UFV, 1997. p. 431-446.

CHACON, E.; STOBBS, T. H.; DALE, M. B. Influence of sward characteristics on grazing behaviour and growth of Hereford steers grazing tropical grass pasture. Australian Journal of Agriculture Research, Melbourne, v. 29 , n. 1, p. 89-102, 1978.

EUCLIDES, V. P. B.; MACEDO, M. C. M.; OLIVEIRA, M. P. Produção de bovinos em pastagens de Brachiaria spp. consorciadas com Calopogonium mucunoides nos cerrados. Revista Brasileira de Zootecnia, Viçosa, MG, v. 27, n. 2, p. 238-245, 1998.

GILLER, K.; CADISCH, G. Future benefits from biological nitrogen fixation: an ecological approach to agriculture. Plant and Soil, Dordrecht, v. 174, p. 255-277, 1995.

GONÇALVES, C. A.; COSTA, N. L. Avaliação agronômica de Brachiaria decumbens em consorciação com leguminosas forrageiras tropicais em Rondônia. Revista da Sociedade Brasileira de Zootecnia, Viçosa, MG, v. 23 , n. 5 , p. 699-708, 1994.

IBRAHIM, M. A.; MANNETJE, L. Compatibility, persistence and productivity of grass-legume mixtures in the humid tropics of Costa Rica - 1: dry matter yield, nitrogen and botanical composition. Tropical Grasslands, St. Lucia, v. 32, p. 96-104, 1998.

JINGURA, R. M.; SIBANDA, S.; HAMUDIKUWANDA, $\mathrm{H}$. Yield and nutritive value of tropical forage legumes grown in semi-arid parts of Zimbabwe. Tropical Grasslands, St. Lucia, v. 35, p. 168-174, 2001.

KLUSMANN, C. Trees and shrubs for animal production in tropical and subtropical areas. Plant Research and Development, Tuebingen, v. 27, p. 92-104, 1988.

LEITE, G. G.; EUCLIDES, V. P. B. Utilização de pastagens de Brachiaria spp. In: SIMPÓSIO SOBRE MANEJO DA PASTAGEM, 11., 1994, Piracicaba. Anais... Piracicaba: Fealq, 1994. p. 267-297.

LEOPOLDINO, W. M. Avaliação nutricional de pastagens consorciadas com legumes tropicais, dinâmica ruminal e produção de leite de vacas mestiças. 2000. 49 f. Dissertação (Mestrado em Zootecnia) - Universidade Federal de Minas Gerais, Belo Horizonte, 2000.

ORSKOV, E. R.; McDONALD, I. The estimation of protein degradability in the rumen from incubation measurements weighted according to rate of passage. Journal of Agricultural Science, Cambridge, Inglaterra, v. 92, p. 499-503, 1979.

PACIULLO, D. S. C.; GOMIDE, J. A.; QUEIROZ, D. S.; SILVA, E. A. M. Composição química, digestibilidade in vitro de lâminas foliares e colmos de gramíneas forrageiras, em função do nível de inserção no perfilho, da idade e da estação de crescimento. Revista Brasileira de Zootecnia, Viçosa, MG, v. 30, n. 3, p. 964-974, 2001. Suplemento 1.

SEIFFERT, N. F.; ZIMMER, A. H. Contribución de Calopogonium mucunoides al contenido de nitrógeno en pasturas de Brachiaria decumbens. Pasturas Tropicales, Cali, v. 10, n. 3, p. 8-13, 1988.

SEIFFERT, N. F.; ZIMMER, A. H.; SCHUNKE, R. M. Reciclagem de nitrogênio em pastagem consorciada de Calopogonium mucunoides com Brachiaria decumbens. Pesquisa Agropecuária Brasileira, Brasília, v. 20, n. 5, p. 529-544, maio 1985 .

SOEST, P. J. van; ROBERTSON, J. B.; LEWIS, B. A. Methods for determination of dietary fiber, neutral detergent fiber, and non starch polysaccharides in relation to animal nutrition. Journal of Dairy Science, Champaign, v. 74, p. 3583-3597, 1991. 